Transportation Research Forum

Industry Issue Paper: GIS Potential in Management of Pedestrian Accidents in Developing Countries Author(s): Mohammed Taleb Obaidat

Source: Journal of the Transportation Research Forum, Vol. 45, No. 1 (Spring 2006), pp. 101-111

Published by: Transportation Research Forum

Stable URL: http://www.trforum.org/journal

The Transportation Research Forum, founded in 1958, is an independent, nonprofit organization of transportation professionals who conduct, use, and benefit from research. Its purpose is to provide an impartial meeting ground for carriers, shippers, government officials, consultants, university researchers, suppliers, and others seeking exchange of information and ideas related to both passenger and freight transportation. More information on the Transportation Research Forum can be found on the Web at www.trforum.org. 


\section{GIS Potential in Management of Pedestrian Accidents in Developing Countries}

The main objective of this work was to investigate the potential of utilizing geographic information systems (GISs) in identifying hazardous pedestrian accident-prone locations. The study was performed for roads in Irbid city-Jordan for the years 2002 and 2003. Pedestrian accident data was analyzed by pedestrian characteristics, driver characteristics, accident time and location, environmental conditions, vehicle speed and characteristics, and accident severity. Pedestrian accidents were correlated to operational factors, including traffic volume, vehicle speed, pedestrian volume, street length, and access points. Hazardous locations of vehicle-pedestrian accidents were identified using a GIS query builder. Results showed that there was a high potential for GISs in studying pedestrian accidents.

\section{by Mohammed Taleb Obaidat}

\section{INTRODUCTION}

One of the important safety issues in developing countries is vehicle-pedestrian accidents. The reasons behind this include serious injuries, fatalities, and economic and social factors. Driving speed is one of the most crucial factors in road safety. Accidents caused by high speed are catastrophic for pedestrians. Pedestrian fatalities are the second leading type of motor vehicle related deaths. For example, Jordan statistics reported by the Jordan Traffic Institute (2000) indicated that about 53,000 traffic accidents occurred during the year 2000, resulting in about 700 deaths and 19,000 injuries. Pedestrians were involved in about $11 \%$ of traffic accidents, which resulted in about $43 \%$ of the deaths and $31 \%$ of the injuries. These numbers and percentages of fatalities and injuries are very high, especially when compared with European Union countries and the United States. For example, pedestrian fatalities as a percentage of total traffic accident fatalities in some of the developed countries were: Belgium $10.4 \%$, Ireland $27.5 \%$, Canada $13.1 \%$, and the United States 12.6\% (Latinopoulou et al. 2001). Developed countries have lower percentages of pedestrian fatalities because almost every pedestrian is a driver, which makes them more familiar with the traffic environment (Choueiri et al. 1993). On the other hand, in Jordan and other developing countries, automobile ownership percentages are lower. Therefore, in urban areas most people walk, which increases the likelihood of people being on the streets and facing the risk of being hit by vehicles. Moreover, due to the congested urban area, vehicle owners prefer to park their vehicles in parking lots and walk to their destinations.

In recent years, planners and researchers have focused their attention on pedestrian accidents, primarily in congested urban areas. In the study area, Irbid-Jordan city, pedestrians use the streets rather than sidewalks for walking. Moreover, the access points for pedestrian crossing have been changed frequently. Therefore, pedestrian safety studies should involve data collection, spatial analysis, and integration of a GIS with statistical models. This is due to the GIS's potential in improving accident location evaluation, plotting accident location, identifying high-risk accident locations, and reasons for and analysis of accident occurrence.

In this paper, a GIS was used as a tool to investigate the potential to find hazardous pedestrian accident-prone locations by studying and analyzing accident characteristics. 
Literature shows that studies of the usage of GISs for pedestrian safety were focused on developed countries, whereas there is a lack of studies in developing countries. In developing countries, knowledge related to pedestrian safety and GISs is minimal. Moreover, in developing countries the behavior of pedestrians while crossing the road at commercial zones is not easy to predict due to: 1) scattered commercial facilities along arterial roads and no location concentrated commercial centers as in developed countries; 2) lack of pedestrian crossings and well marked facilities, and their incorrect distribution of locations, or spacing along arterials; 3 ) narrow sidewalks that force pedestrians to cross the road anywhere; and 4) lack of public awareness safety programs for pedestrians.

\section{LITERATURE REVIEW}

Safety in urban areas could be improved through development of criteria to identify high pedestrian accident locations. These locations would help planners and decision makers establish pedestrian safety programs (i.e., traffic calming, pedestrian crossing facilities, or vertical separators) and give a better understanding of the causes of pedestrian accidents. A GIS could help in this domain because it has spatial analysis capabilities.

Several studies have cited the potential of GISs in plotting vehicle-pedestrian accident locations and identifying high-risk locations of urban areas (Baltes 1998; Cui 2000; and Schneider et al. 2001). A GIS could be utilized in safety studies because it has the capabilities of performing spatial analysis and mapping analysis, follow-up and updating tasks, and identifying and querying for any contributing factors to reduce accidents. Schneider et al. (2002) utilized GISs in some database operations and a statistical spatial method in order to integrate data of pedestrian accident reports and survey data. They categorize pedestrian accidents according to pedestrian characteristics (gender, age, and ethnicity), types of accidents (involving alcohol, disregarding a traffic signal, and crossing at mid block crosswalk) and event conditions (date, time, location, urban, rural, weather, and surface conditions). Crash data (i.e., annual average number of crashes per million vehicles divided by the average daily traffic volume) was geocoded to the street network in a GIS format to define locations and types of crashes. Location crash rate was compared to the critical crash rate and the location was assigned as a high-crash location if its crash rate is greater than or equal to the critical crash rate (i.e., an optimal value for number of crashes per million vehicles divided by the average daily traffic volume). This optimal value varies by country depending on safety policy, lifestyle level, and traffic infrastructure.

Studies showed that metropolitan transit corridors with large numbers of bus stop users resulted in increased exposure of pedestrians to traffic and more pedestrian-vehicle accidents (Southworth and Owens 1993, and Small et al. 1995). They suggested that streets with high numbers of bus riders need to accommodate people walking safely along and across the roadway. Moreover, bus stop usage was associated with pedestrian accidents near parking facilities.

Al-Masaeid et al. (1997) studied the spatial distribution of pedestrian accidents in Irbid city, Jordan, from 1993 to 1995. They developed a negative binomial regression model in order to predict pedestrian accident frequency at midblocks (the distance between two sequential intersections) of arterial roads using the following independent variables: peak traffic flow, mid-block number of public buildings frontage along the arterial, mid-block percentage of commercial area along the arterial, mid-block percentage of green areas along the arterial, sidewalk width, and parking conditions. They found that pedestrian accidents are concentrated along major urban arterials, which accounted for $64 \%$ of pedestrian accidents of which $74 \%$ occurred within mid-block areas.

Several studies cited GIS benefits and potential for planners and engineers in managing, analyzing, and reporting pedestrian accident locations and high-risk areas (U.S. Department of Transportation, Bureau of Transportation Statistics 2000; and Schneider 2001).

Literature also showed that pedestrians not owning vehicles and pedestrians who parked 
their vehicles at parking facilities had more vehicle-pedestrian collisions. Therefore, it was important to have a vacant parking space near the pedestrian's destination in order to minimize walking distance. This means that vacant parking spaces located near the pedestrian's destination potentially would decrease vehiclepedestrian accidents (Small et al. 1995).

Obviously, the literature shows a great impact of vehicle-pedestrian accidents on pedestrian safety and metropolitan area planning. Traffic, geometric, land-use, and pedestrian behavior variables had the greatest impact on pedestrian accidents. Therefore, a GIS was used in this work to study its potential to analyze the pedestrian safety issue in Jordan, a developing country.

\section{GIS DATA COLLECTION}

Pedestrian traffic accident data were obtained from original reports of the traffic directorate and public security headquarters in Irbid city for 2002 to 2003. After reviewing the traffic accident reports for the study period, 796 pedestrian accidents reports were separated from about 6,000 traffic accident reports that included all types of accidents with some accidents that occurred outside the borders of Irbid city. Only 395 pedestrian accidents occurred during street crossing.

The following were the major data items that existed in the accident report and helped in analyzing pedestrian accidents, therefore, they were used in the attributes of the GIS themes:

1. Accident related data, including location, severity (slight, medium, severe injury or fatality), time (day, week, month, and year), illumination condition (daylight, night with sufficient light, night with insufficient light, or dark), road surface condition (dry, wet, snowy, icy, flooded, or muddy), and weather condition (clear, fog, rain, snow, strong wind, dust, or other).

2. Pedestrian related data, including age and gender.

3. Driver related data (age and gender), and license type (no license, type 1, 2, 3, 4, 5, 6,7 , or foreign license).

4. Vehicle category (motor cycle, agricultural vehicle, construction vehicle, small passenger car, minibus, bus, truck, dual-purpose vehicle, or special purpose vehicle), and type (foreign, government, private, public, military, or recreation).

5. Speed limit (30-70 kilometers per hour).

6. Pedestrian action (crossing in front of parked vehicle, walking, running, cycling, off road, approaching or leaving vehicle, playing on the road, pushing or towing a carriage, walking on sidewalk, working in the road, or crossing the road).

7. Driver fault (not giving priority to pedestrian, failing to comply with obligatory signs, incorrect reversing, exceeding speed limit, incorrect bending and turning, not giving priority to vehicles, using incorrect lane, driving opposite to traffic direction, incorrect overtaking, driving under the influence of alcohol, incorrect parking, or disregarding a traffic light signal).

It must be noted here that about $30 \%$ of the data related to location of accidents were estimated because some of the accident reports did not include the exact location.

\section{GIS LAYERS}

Pedestrian accident GIS layers (themes) were developed for the studied period in order to identify entities, attributes, and relationships of variables. The following attributes were used for each layer:

- Shape: the type of shape of the specific pedestrian accident location (Point). A vector GIS uses points, arcs, and areas to display location of objects. Point shape was used to represent features (pedestrian accidents) that have a specific location on a horizontal plane. Points could have their size, shape, and color varied to suggest importance.

- Attributes: Accident location (street name, mid-block, or at intersection, and roadway classification), speed limit $(\mathrm{km} /$ $\mathrm{hr}$ ), pedestrian crossing action, pedestrian accident time (hour, time of day, date, and month), injury information (number of injuries, gender, age, and severity), driver information (age, gender, and license type), vehicle information (category and type), and environmental conditions (road 
surface condition, illumination level, and weather condition).

Tables 1 and 2 show samples of the collected database of pedestrian accidents.

\section{GIS SCHEME AND VEHICLE PEDESTRIAN ACCIDENT LOCATIONS}

The Arcview software package was utilized to find hazardous accident locations (ESRI 1997). Using the query option, accident features and records could be selected. Information about accident features, selection of them directly and according to their attributes, one at a time and in groups, is possible. Therefore, pedestrian accident features based on their attributes could be selected using any combination of logical operators (AND, OR, or EQUAL) between variables.

A GIS-based procedure was developed to perform identification, query, and statistical analysis, and to analyze characteristics and spatial distribution of vehicle-pedestrian accidents. Moreover, hazardous vehiclepedestrian accident locations could be found using the query builder concept. Therefore, digital format and spatial maps could be displayed in real time for the most frequent and high-risk pedestrian accident locations.

The developed GIS-based methodology to find hazardous pedestrian accident locations could be done through the following steps:

1. Build a pedestrian accident database.

2. Define variables and their respective attributes.

3. Build a pedestrian accident spatial features map.

4. Use a GIS to link between a spatial map and associated database.

5. Define selection color.

6. Use GIS query builders to classify pedestrian accidents based on any selected attribute.

7. Identify high-risk pedestrian accident locations.

8. Build spatial maps of most frequent or high-risk pedestrian accident locations based on posted speed, location, pedestrian age and gender, road and weather condition, accident severity, time and date of accident, driver age and gender, license type, and vehicle type and category.

9. Group different query combinations for the studied attributes.

10. Give guidelines and precautions for pedestrian crossing.

11. Construct appropriate pedestrian crossing facilities.

It is worthwhile mentioning here that the high-risk (high severity level) pedestrian accident locations could be queried and manipulated for the following variables:

1. A specified distance of a selected road.

2. Frequency and severity of accidents.

3. Roads of specified speed.

4. Traffic volume.

5. Accident per vehicle $\mathrm{km}$ traveled.

6. Spot location, mid-block, or at intersection accident.

7. Number of pedestrian access points.

8. Pedestrian gender, age, and injury severity.

9. Weather and lighting conditions.

10. Any traffic characteristics.

11. Combinations of all of above.

Of course, defining the high severity accident locations would help guide the allocation of funds for safety improvements, assist with planning and pedestrian perception survey studies, provide better understanding of accident causes, and help design operating strategies and programs for pedestrian safety enhancement. It also could help improve pedestrian safety by providing users, pedestrians, drivers, and police with digital map-based computer pedestrian accident data. Pedestrian safety analysis is the final product of the GIS tool.

Practical applications of how the developed GIS scheme would assist planners in improving pedestrian safety include:

1. Helping planners select safer locations of crossing facilities.

2. Minimizing commercial zones, schools, and land use effects that attract pedestrians along arterial roads.

3. Improving crossing facilities of hazardous locations. For example, changing the location and the geometry of crossing facilities or the spacing between them.

4. Minimizing the number of pedestrian crossing facilities along arterials of high traffic volume. 
Pedestrian Accidents

Table 1: Pedestrian Accident Data Sample for the Year 2003

\begin{tabular}{|c|c|c|c|c|}
\hline Accident Location & $\begin{array}{l}\text { Location } \\
\text { Type }\end{array}$ & $\begin{array}{l}\text { Roadway } \\
\text { classification }\end{array}$ & $\begin{array}{c}\text { Speed } \\
\text { Limit (km/ } \\
\text { hour) }\end{array}$ & Pedestrian Action \\
\hline Abdul Al-Qader Al-Husini St. & Mid-Block & Secondary & 40 & Crossing the road \\
\hline Abdul Hamid Sharaf & Intersection & - & 50 & Crossing the road \\
\hline Abdul Hamid Sharaf Squire. & Intersection & - & 50 & Crossing the road \\
\hline Abdul Hamid Sharaf Squire. & Intersection & - & 50 & Crossing the road \\
\hline Abdul Hamid Sharaf St. & Mid-Block & Arterial & 50 & Crossing the road \\
\hline Abdul Hamid Sharaf St. & Mid-Block & Arterial & 50 & Crossing the road \\
\hline Abdul Hamid Sharaf St. & Mid-Block & Arterial & 50 & Crossing the road \\
\hline Abdul Hamid Sharaf St. & Mid-Block & Arterial & 50 & $\begin{array}{l}\text { Crossing in front of } \\
\text { parked vehicle }\end{array}$ \\
\hline Abdul Qader Al-Tal & Intersection & - & 40 & Crossing the road \\
\hline Abdullah Al-Tal St. & Mid-Block & Local & 30 & $\begin{array}{l}\text { Crossing in front of } \\
\text { parked vehicle }\end{array}$ \\
\hline Abi Al-Nwas St. & Mid-Block & Local & 30 & Crossing the road \\
\hline Abi Thar Algafari St. & Mid-Block & Local & 30 & Crossing the road \\
\hline Al-Aghwar Terminal & Mid-Block & Local & & Crossing the road \\
\hline Al-Agwar St. & Mid-Block & Arterial & 70 & Crossing the road \\
\hline Al-Agwar St. & Mid-Block & Arterial & 70 & Crossing the road \\
\hline Al-Agwar St. & Mid-Block & Arterial & 70 & Crossing the road \\
\hline Al-Arous St. & Mid-Block & Secondary & 40 & Crossing the road \\
\hline Al-Awdeh St. & Mid-Block & Local & 30 & Crossing the road \\
\hline Al-Bariha & Intersection & - & 40 & Crossing the road \\
\hline Al-Bariha & Intersection & - & 40 & Crossing the road \\
\hline Al-Bariha & Intersection & - & 40 & Crossing the road \\
\hline Al-Bariha St. & Mid-Block & Secondary & 40 & $\begin{array}{l}\text { Crossing in front of } \\
\text { parked vehicle }\end{array}$ \\
\hline Al-Bariha St. & Mid-Block & Secondary & 40 & $\begin{array}{l}\text { Crossing in front of } \\
\text { parked vehicle }\end{array}$ \\
\hline Al-Bariha St. & Mid-Block & Secondary & 40 & Crossing the road \\
\hline Al-Bariha St. & Mid-Block & Secondary & 40 & Crossing the road \\
\hline Al-Bariha St. & Mid-Block & Secondary & 40 & Crossing the road \\
\hline Al-Bariha St. & Mid-Block & Secondary & 40 & Crossing the road \\
\hline Al-Bariha St. & Mid-Block & Secondary & 40 & Crossing the road \\
\hline Al-Emam Malek St. & Mid-Block & Local & 30 & Crossing the road \\
\hline Al-Hamaydeh St. & Mid-Block & Local & 30 & Crossing the road \\
\hline
\end{tabular}


Table 2: Sample of Attributes for Pedestrian Accident Layer

\begin{tabular}{ccccccccccc}
\hline $\begin{array}{c}\text { Accident } \\
\text { Number }\end{array}$ & Time & Time scale & Date & Month & $\begin{array}{c}\text { Injury } \\
\text { No. }\end{array}$ & $\begin{array}{c}\text { Injury } \\
\text { Age }\end{array}$ & $\begin{array}{c}\text { Injury } \\
\text { Gender }\end{array}$ & Severity & $\begin{array}{c}\text { Driver } \\
\text { Age }\end{array}$ & $\begin{array}{c}\text { Driver } \\
\text { Gender }\end{array}$ \\
\hline 1 & $18: 15$ & Evening & $1 / 19$ & 3 & 1 & 3 & Male & Slight & 28 & Male \\
3 & $16: 30$ & Afternoon & $1 / 1$ & 7 & 1 & 4 & Female & Slight & 32 & Male \\
4 & $12: 30$ & Noon & $1 / 12$ & 6 & 1 & 5 & Female & Slight & 19 & Male \\
5 & $19: 00$ & Evening & $1 / 13$ & 1 & 1 & 3 & Male & Slight & 27 & Male \\
6 & $12: 00$ & Noon & $1 / 19$ & 3 & 1 & 3 & Male & Slight & 39 & Male \\
7 & $07: 30$ & Mourning & $1 / 20$ & 5 & 1 & 3 & Male & Slight & 51 & Male \\
8 & $13: 30$ & Noon & $1 / 21$ & 5 & 1 & 3 & Male & Slight & 20 & Male \\
9 & $20: 00$ & Night & $11 / 22$ & 3 & 1 & 45 & Male & Slight & 34 & Male \\
10 & $13: 30$ & Noon & $1 / 30$ & 11 & 1 & 5 & Male & Slight & 32 & Male \\
11 & $20: 30$ & Evening & $1 / 7$ & 9 & 1 & 20 & Female & Slight & 40 & Female \\
12 & $21: 30$ & Night & $1 / 7$ & 1 & 1 & 12 & Female & Slight & 40 & Male \\
13 & $16: 00$ & Afternoon & $1 / 10$ & 3 & 1 & 24 & Female & Medium & 36 & Male \\
14 & $20: 30$ & Night & $1 / 12$ & 6 & 3 & 2 & Female & Slight & 26 & Male \\
\hline
\end{tabular}

Table 2: continued

\begin{tabular}{|c|c|c|c|c|c|c|}
\hline $\begin{array}{l}\text { Accident } \\
\text { Number }\end{array}$ & $\begin{array}{c}\text { Driver License } \\
\text { type }\end{array}$ & $\begin{array}{l}\text { Vehicle } \\
\text { Category }\end{array}$ & $\begin{array}{l}\text { Vehicle } \\
\text { type }\end{array}$ & $\begin{array}{l}\text { Road surface } \\
\text { condition }\end{array}$ & $\begin{array}{c}\text { Illumination } \\
\text { Level }\end{array}$ & $\begin{array}{l}\text { Weather } \\
\text { Condition }\end{array}$ \\
\hline 1 & 3 & Passenger & Private & Dry & Day light & Clear \\
\hline 3 & 3 & Passenger & Private & Dry & Day light & Clear \\
\hline 4 & 3 & Dual purpose & Private & Dry & Day light & Clear \\
\hline 5 & 4 & Passenger & Public & Dry & Day light & Clear \\
\hline 6 & 4 & Passenger & Private & Dry & Day light & Clear \\
\hline 7 & 6 & Truck & Public & Dry & Day light & Clear \\
\hline 8 & 3 & Truck & Private & Dry & Day light & Clear \\
\hline 9 & 6 & Passenger & Public & Dry & Day light & Clear \\
\hline 10 & 4 & Passenger & Public & Dry & Day light & Clear \\
\hline 11 & 3 & Passenger & Private & Dry & Day light & Clear \\
\hline 12 & 3 & Passenger & Private & Wet & Day light & Rain \\
\hline 13 & 3 & Dual purpose & Private & Dry & Day light & Clear \\
\hline 14 & 4 & Truck & Private & Dry & Day light & Clear \\
\hline
\end{tabular}


INTEGRATION OF GIS AND ANALYTICAL MODELING

Although GISs have sophisticated database operations and data manipulation, their statistical methods are limited to mean and standard deviation of the studied variables. Therefore, for pedestrian safety studies that involve spatial analysis and accident data collection, there is a need to use statistical spatial methods (such as regression analysis) in order to integrate data from different sources.

GIS has the potential to turn accident statistical data, such as number of pedestrian accidents, and geographic data, such as roads and accident locations, into useful information for the purpose of mapping and spatial analysis. Further, GISs can assist in identifying factors contributing to the occurrence of those accidents. Those factors were identified in the developed "GIS Scheme" section.

Numerous decision-making and management tasks could be performed using the integration concept of GIS and analytical modeling:

1. Safe operation of pedestrian crossings.

2. Establishment of pedestrian safety programs.

3. Prediction of the number of pedestrian accidents and their locations.

4. Geometric layout of access points on roads.

5. Fund allocation for pedestrian safety studies.

6. Types of pedestrian crossing facilities.

Using these analyses, management strategies could be developed to reduce pedestrian accidents such as:

1. Construction of formal crossings (pedestrian crossing marking) or vertical separator (underpass or overpass facilities) pedestrian crossing facilities.

2. Construction of wider sidewalks and encouraging pedestrians to use them instead of streets.

3. Use of traffic calming measures (lower speed limit, humps, or bumps).

4. Selection of number and location of pedestrian crossing facilities.

Having a GIS spatial map for the urban street network and using analytical modeling, it is possible to locate the access points and their associated predicted numbers of pedestrian accidents. Therefore, based on high-risk accident locations of GIS queries, the number of access points could be reduced using a selected threshold value. Usually political decisions are made to limit the number of access points to three to five for each arterial road (i.e., a distance of about 50 to 70 meters between every two successive crossing facilities).

\section{DISCUSSION AND ANALYSIS}

Defining the spatial maps for hazardous pedestrian crossing locations is very important from the perspective of pedestrian safety, convenience, and traffic jam issues.

The developed GIS-based scheme, for the purpose of finding the severe vehicle-pedestrian accident locations, could give insight to the pedestrian safety problem. The developed maps using this scheme could be updated and be useful for planning purposes. Establishing guidelines for pedestrian safety program effectiveness through educational, engineering, and enforcement treatment could do this. The guidelines are anticipated to report and countermeasure dangerous accidents quickly, make appropriate educational or engineering countermeasures, make safety improvements at severe injuries locations, and design a quick response rescue system for pedestrians and drivers at high-risk accident locations. The guidelines could also be useful for city planners and traffic engineers to identify highrisk access points and advise pedestrians who use them. The results of query maps could also be provided to police, pedestrians, drivers, and citizens in order to inform them about highrisk pedestrian accident locations or locations that have high potential for future pedestrian accidents. In fact, spatial analysis using query options could identify the characteristics of dangerous pedestrian accidents, such as type, pedestrian gender, age, injury severity, time and date, and weather conditions. Combination of different queries would result in a more accurate assessment of high-risk pedestrian accident locations and improvement of pedestrian safety. Moreover, developing a street network characterized by few access points could be a great advantage for city planners and traffic engineers because this would enhance traffic 
flow and improve the quality of traffic service.

The number of pedestrian accidents depends on number of access points in the roadway; however, vehicle speed, pedestrian volume, and average daily traffic (ADT) are important as well. Congested times of day and streets with higher speed limits had the highest percentage of accidents. Figures 1 and 2 show pedestrian accidents as a function of the time of the day and speed limit. Obviously, the 12 a.m. to 4 p.m. time period and a speed limit of $50 \mathrm{~km} /$ hr had the highest percentages of accidents due to traffic congestion and pedestrian movement. Table 3 shows the number of access points and pedestrian accidents of the streets with a high number of severe accidents. The number of access points ranged from 4 to 15 pedestrian crossing locations for every arterial road. The high number of access points increases vehiclepedestrian conflict and accident potential that makes them locations with a large number of severe pedestrian accidents.

If query builder procedure is used along with statistical modeling, it is anticipated to have numerous advantages such as:

1. Optimization potential of pedestrian crossing behavior.

2. Time saving for pedestrians.

3. Safety potential for pedestrians.

4. Decision making potential for city planners.

Table 3: Characteristics of Most Frequent Vehicle-Pedestrian Accident Streets

\begin{tabular}{lcccc}
\hline \multicolumn{1}{c}{ Accident Location } & $\begin{array}{c}\text { Number of } \\
\text { Accidents } \\
(\mathbf{2 0 0 2})\end{array}$ & $\begin{array}{c}\text { Number of } \\
\text { Accidents } \\
(\mathbf{2 0 0 3 )}\end{array}$ & Access Points & $\begin{array}{c}\text { Speed } \\
\text { (km/hour) }\end{array}$ \\
\hline King Hussien St. & 27 & 16 & 12 & 50 \\
Palestine St. & 23 & 8 & 10 & 50 \\
Shafeq Arsheidat St. & 18 & 12 & 10 & 50 \\
Abdul Hamid Sharaf & 17 & 7 & 15 & 40 \\
Al-Bariha St. & 14 & 10 & 15 & 40 \\
Al-Hakmeh St. & 7 & 9 & 4 & 60 \\
Al-Quds St. & 5 & 10 & 6 & 50 \\
Wasfi Tall St. & 9 & 5 & 9 & 40 \\
Balat Al-Shuhada' St. & 5 & 8 & 7 & 40 \\
Omar Al-Mukhtar St. & 5 & 8 & 5 & 50 \\
Fo'arah St. & 1 & 9 & 5 & 70 \\
Bushra St. & 2 & 7 & 8 & 40 \\
King Fysal Athani St. & 6 & 3 & 7 & 50 \\
Al-Razi St. & 6 & 2 & 7 & 50 \\
Al-Huson St. & 4 & 3 & 10 & 40 \\
\hline
\end{tabular}


Figure 1: Pedestrian Accidents as Function of the Time of the Day

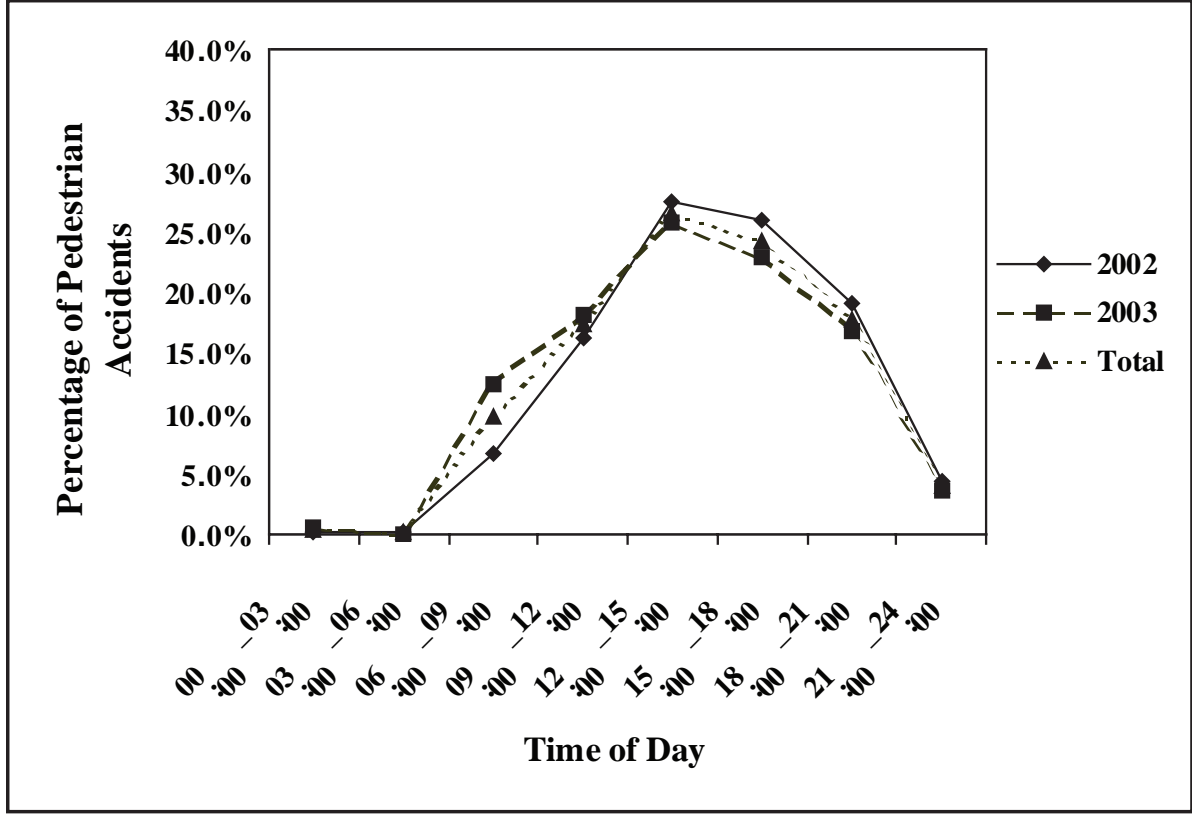

Figure 2: Pedestrian Accidents as Function of the Speed Limit

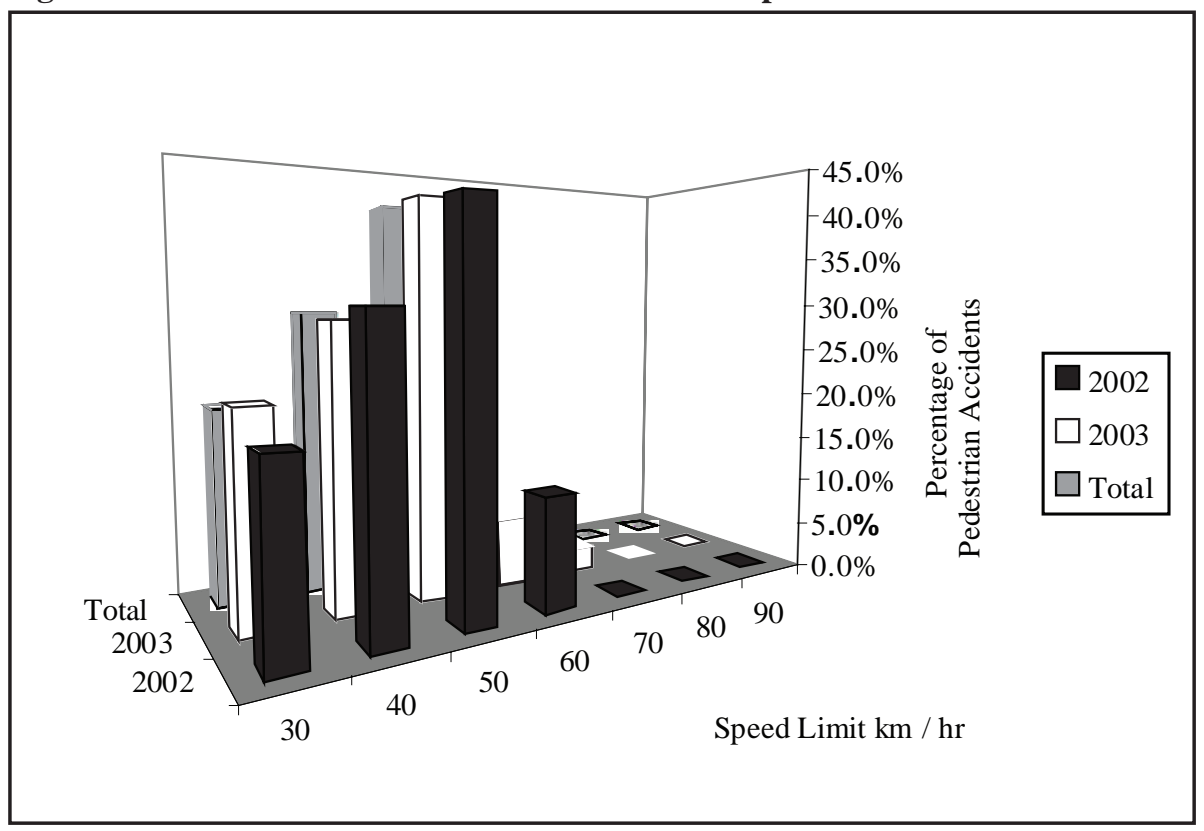




\section{CONCLUSIONS AND}

\section{RECOMMENDATIONS}

In developing countries, traffic departments do not give pedestrian safety enough attention. They install speed humps wherever severe pedestrian accidents occur, thinking that speed is the only contributing factor in the occurrence of pedestrian accidents. The potential of GISs in the analysis of pedestrian accidents was demonstrated. GIS layers were built for different pedestrian accident attributes, such as accident location, vehicle data, pedestrian data, environmental data, driver's data, and roadway classification.

It was found that GIS query could be used as a viable tool to develop a new scheme in order to find hazardous pedestrian accident locations regardless of the number of constraints and combinations of attributes. Spatial digital maps were demonstrated to show severe pedestrian accident locations. The developed GIS-based scheme has the advantages of flexibility, practicality, time saving, safety potential, and ease-of-use guidelines for city planners and decision makers.

The findings of this work are anticipated to improve pedestrian safety, give guidelines and precautions for pedestrians to control their road crossing, and identify hazardous locations for pedestrian accidents. Moreover, planners and traffic engineers will benefit from this study to construct the appropriate number of pedestrian crossings.

Regardless of the useful findings of this research work that was introduced through GIS technology, many things should be done to enhance pedestrian safety in the Third World countries. These include focusing on educational and enforcement programs for drivers, providing children with road safety skills, avoiding school locations at arterial roads of high $\mathrm{ADT}$, developing appropriate cross walks, increasing refuge islands, utilizing GIS as a training and educational facility, evenly distributing parking lots (especially near public buildings), and providing enough parking space. This will indeed make planners realize that blaming drivers is not the only way to prevent pedestrian accidents or improve pedestrian safety. However, public awareness campaigns, re-engineering of roads, including safer intersection design, educating drivers, defining danger times of high-risk locations, providing parking policies, and monitoring traffic techniques could also be other factors that contribute to pedestrian safety. 


\section{References}

Al-Masaeid, H., M. T. Obaidat, and F. Gharaybeh. "Pedestrian Accidents Along Urban Arterial Mid-blocks.” Journal of Traffic Medicine 25(3), (1997):65-70.

Baltes, M. R. "Descriptive Analysis of Crashes Involving Pedestrians in Florida, 1990-1994.” Transportation Research Record 1636, (1998):138-145.

Choueiri, E., R. Lamm, and B. Choueiri. “Pedestrian Accidents.” ITE Journal July, (1993):36-42.

Cui, Z. “GIS-based Evaluation of Mid block Pedestrian Crossing Safety.” M.Sc. Thesis, University of Nevada, Las Vegas, 2000.

ESRI, "Getting to Know Arc View GIS: The Geographic Information System (GIS) for Everyone." GeoInformation International, 2nd edition, 1997.

Jordan Traffic Institute. Traffic Accidents in Jordan, 2000

Latinopoulou, M., G. Tsohos, S. Basbas, and A. Kokkalis. "Investigation of Accidents Involving Vulnerable Road Users in Greek Urban Areas.” Proceedings of the Conference: Traffic Safety on Three Continents. Moscow, Russia, (2001):176-182.

Schneider, R. J. "Development of a Proactive Approach to Pedestrian Safety Planning.” A Masters Project. University of North Carolina at Chapel Hill, 2001.

Schneider, R. J., A. J. Khattak, and C. V. Zegeer. "Method of Improving Pedestrian Safety Proactively with Geographic Information Systems.” Transportation Research Record 1773, (2001):97-107.

Schneider, R. J., A. J. Khattak, and R. M. Ryznar. "Factors Associated with Pedestrian Crash Risk: Integrating Risk Perceptions and Police-Reported Crashes.” Transportation Research Board, 2002.

Small, K., R. Noland, and P. Kuskenoje. "Socio-Economic Attributes and Impacts of Travel Reliability: A Stated Preference Approach.” Unpublished report, University of California, Irvine, 1995.

Southworth, M. and P. Owens. "The Evolving Metropolis: Studies of Community, Neighborhood, and Street Form at the Urban Edge.” Journal of the American Planning Association 59 (3), (1993):271-287.

U.S. Department of Transportation, Bureau of Transportation Statistics. "Bicycle and Pedestrian Data: Source, Needs, and Gaps.” Washington D.C., 2000.

Mohammed Taleb Obaidat is an associate professor of civil engineering at Jordan University of Science and Technology (J.U.S.T.), Jordan, where he teaches courses in geomatics, photogrammetry, surveying, GIS, remote sensing, transportation engineering, and computer vision. He received a B.Sc. in civil engineering with honors from Yarmouk University, Jordan in 1983; an M.Sc. with honors in transportation engineering from J.U.S.T. in 1988; and both an M.Sc. and Ph.D. with honors in geomatics and computer vision from the University of Illinois at Urbana-Champaign in 1994. Obaidat was awarded the Leica Inc. Fellowship from the American Society for Photogrammetry and Remote Sensing in 1992; the medal of research and academic achievement from his majesty King Husein Ben Talal of Jordan, 1997; and the Scientific Foundation of Hisham Hijjawi for applied science award, 1998.

Dr. Obaidat has published more than 40 scientific articles in refereed, specialized, and indexed journals and proceedings of international conferences. Obaidat was dean of student affairs at J.U.S.T. (1999-2004). He currently serves as an advisor to the minister of higher education and research for student affairs, Ministry of Higher Education and Research-Jordan. 